\title{
The Importance of Daily Activity for Reducing Fibromyalgia Symptoms: A Retrospective "Real World" Data Comparison of two Multimodal Treatment Programs
}

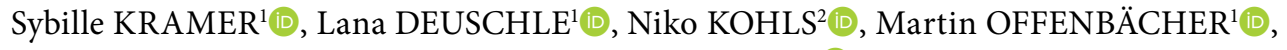 \\ Andreas WINKELMANN ${ }^{1}$ (D) \\ ${ }^{1}$ Department of Orthopaedics, Physical Medicine and Rehabilitation, University of Munich, Munich, Germany \\ ${ }^{2}$ Division of Integrative Health Promotion, University of Applied Sciences and Art, Coburg, Germany
}

\begin{abstract}
Objectives: This study aims to evaluate the effectiveness of two multidisciplinary fibromyalgia programs with different intensities.

Materials and methods: In this retrospective real-world comparison of patient data, pre- and post-program datasets of Short Form 36 (SF36) and Fibromyalgia Impact Questionnaire (FIQ) were obtained from a total of 210 female patients in two fibromyalgia multidisciplinary day hospital programs including one intensive program with daily treatments summing up to 20 treatment days during four weeks (P20, $n=70)$ versus a less intensive program with 12 treatment days during four weeks ( $P 12, n=140)$.

Results: Multiple subscales of SF36 and FIQ were improved in the pre-post comparison in both groups. In the comparison between the two groups, a statistically significantly higher improvement was found in the P20 group compared to the P12 group for the FIQ subscales of stiffness ( $p=0.001$ ) and the number of days during which the patient felt "good" ( $p=0.007)$.

Conclusion: An intensive program of daily treatments and activity seems to be more effective in reducing fibromyalgia-associated stiffness and improving the number of days during which patients feel good than a less intensive program.

Keywords: Chronic widespread pain, multicomponent, multidisciplinary, multimodal, multiprofessional.
\end{abstract}

Fibromyalgia is a chronic pain syndrome that is characterized by a broad number of clinical symptoms such as widespread pain, poor sleep, fatigue, psychological distress, functional disability, and cognitive impairment. It severely compromises patients' quality of life and produces significant costs for health systems. ${ }^{1,2}$ To date, both the etiology and pathogenetic pathways remain widely unknown. Diagnosis is predominantly based on the clinical assessment following the American College of Rheumatology (ACR) criteria ${ }^{3}$ and after exclusion of other somatic diseases such as hypothyroidism, rheumatoid arthritis, systemic lupus erythematosus or other inflammatory or autoimmune disorders which may explain the symptoms.

A wide range of pharmacological and non-pharmacological treatments are offered including antidepressants, anticonvulsants or transcutaneous nerve stimulation. Additionally, various behavioral therapies, health promotion, and integrative medical interventions such as meditation, various diets, and acupuncture have

Received: August 01, 2019 Accepted: December 04, 2019 Published online: April 17, 2020

Correspondence: Sybille Kramer, MD. Department of Orthopaedics, Physical Medicine and Rehabilitation, University of Munich, 81377 Munich, Germany. Tel: 0049-89-4400-52402 e-mail: sybille.kramer@med.uni-muenchen.de

Kramer S, Deuschle L, Kohls N, Offenbächer M, Winkelmann A. The Importance of Daily Activity for Reducing Fibromyalgia Symptoms: A Retrospective "Real World" Data Comparison of two Multimodal Treatment Programs. Arch Rheumatol 2020;35(4):575-583. 
been utilized as treatment options. The scientific evidence for the efficacy of the listed interventions remains poor. -12 $^{-12}$ Consequently, the range of recommended treatment options is limited..$^{13,14}$

The best-established approach for easing fibromyalgia symptoms is multicomponent treatment programs. In multicomponent or multimodal programs, professionals of different disciplines provide expertise and treatment from different fields. Physicians, psychologists, physiotherapists and others work synergistically for optimal treatment effects. Multimodal treatments can be conceptually different, depending on whether their design is multidisciplinary or interdisciplinary. In multidisciplinary treatments, professionals remain within their field of expertise, whereas in interdisciplinary treatments, they are coordinated towards a common aim. ${ }^{15}$ Although there is no data on whether multi- or interdisciplinarity is more effective, there exists some scientific evidence for multicomponent treatment programs in general ${ }^{16}$ and multicomponent programs are strongly recommended in the latest German guidelines. ${ }^{17}$

The uncertainty concerning effectiveness is further complicated by the fact that these programs are very heterogeneous in terms of duration, objectives, setting, format, therapeutic components, and professionals involved. A recent review of fibromyalgia treatment programs listed interventions with a median duration of seven weeks. However, this review covered durations from very short periods lasting for less than a week up to very long periods lasting for one year. With regards to treatment intensity, there were both intensive programs and lessintensive interventions with less than 12 hours of therapies. ${ }^{18}$

Given this diversity, any judgment about the most suitable intervention intensity for patients is challenging. Therefore, in this study, we aimed to evaluate the effectiveness of two multidisciplinary fibromyalgia programs with different intensities.

\section{MATERIALS AND METHODS}

In this retrospective analysis, data from 70 female patients (mean age 50.2 \pm 9.9 ) participating in a 20-day multidisciplinary rehabilitation program (four weeks, five days per week, P20) at the tertiary fibromyalgia day care center of the department of Physical Medicine and Rehabilitation (PMR) at Department of Orthopedics, Physical Medicine and Rehabilitation, University Hospital, LMU Munich between December 2012 and March 2015 were evaluated and compared to those of 140 patients (mean age 59.5 \pm 7.7 ) who participated in the former (running between 1999 and 2012) 12-day fibromyalgia program (four weeks, three days per week, P12) consisting of similar therapeutic elements as the 20-day version. The study protocol was approved by the ethics committee of the University of Munich and the ethics committee of the University of Applied Science and Arts of Coburg. The study was conducted in accordance with the principles of the Declaration of Helsinki.

Inclusion criteria for both programs were a diagnosis of fibromyalgia according to the ACR criteria for FMS and being aged $\geq 18$ years. Patients with cardiac, respiratory, gastrointestinal, renal, hematological disorders, neurological, or psychiatric disorders too severe to participate in physical exercises or balneotherapy were excluded. Patients with a pending application for disability pension were also excluded due to potential bias. Only complete pre-post datasets of the patients were included in the analysis $(n=133$ $\mathrm{p}-12, \mathrm{n}=67 \mathrm{p}-20)$.

In the interdisciplinary day hospital programs, various professionals (medical doctors specialized in physical and rehabilitative medicine, physiotherapists, occupational therapists, balneoand hydrotherapists, occupational therapists and psychotherapists) provided a therapy program in a group setting. The programs included different therapeutic elements for a duration of four weeks. Each patient attended the program for seven hours per day (except on Fridays for 5.4 hours). Additional individual medical and psychological consultations were available on demand.

Patients received medical and psychoeducational information about fibromyalgia, medical nutritional advice, and psychotherapy group sessions utilizing a cognitive-behavioral approach. On the physical side, the different physiotherapeutic elements aimed to improve strength, endurance, agility, and coordination. Therefore, the physiotherapeutic 
units consisted of a light warm-up with endurance training, followed by strengthening training, stretching exercises, and coordination (including stabilizing and balancing) training. The different exercises were easy to learn in order to encourage home exercising. Relaxation was performed in different physiotherapeutic or psychological units. Perception training was performed with QiGong exercises. Ergotherapy included psychoeducative exercises to distract patients from their pain perception, guidance to joint-saving behavior, advice regarding medical accessories, and fatigue assessment. Balneotherapy consisted of hot and cold packs, hydroelectric baths, and electrotherapy including transcutaneous nerve stimulation. Table 1 displays the different components and their proportion of each program.

Interdisciplinarity was underpinned by weekly team meetings to coordinate the individual therapeutic approach under behavioral aspects (self-help centered), and to ensure focusing on better function during activities of daily living, quality of life, and symptom management. Pharmacological therapy was not a part of the day hospital program. On the contrary, it was part of the concept not to change any pharmacological management during participation. Any necessary adaptation of the medication was performed either before or after the program.

Questionnaires including the following selfreported variables were administered to the patients on the first day of the program: marital status, age, level of education, and household income. Data on the duration of symptoms indicative of FMS were also collected.

The questionnaire set included the Fibromyalgia Impact Questionnaire (FIQ) and the
Short Form 36 (SF36). Both were administered to the patients on the first and the last day of the programs. The FIQ is an assessment and evaluation instrument developed to measure fibromyalgia patients' status, progress, and outcomes. It was designed to measure the components of health status that are believed to be most affected by fibromyalgia. The total score ranges from 0 to 80 points based on physical functioning, number of "days felt good", pain, fatigue, morning tiredness, stiffness, anxiety, and depression. A score of 80 indicates maximum fibromyalgia impact. The FIQ was used in the validated German version. ${ }^{19}$ The SF36 is a 36-item instrument for measuring health status and outcomes from the patient's perspective and is available in numerous validated languages including German. ${ }^{20,21}$ The SF36 consists of eight multi-item scales plus a single item to assess health transition. Its subscales allow for an evaluation of physical functioning, physical role functioning, bodily pain, general health perceptions, vitality, social role functioning, emotional role functioning, and mental health. Additionally, two summary scales are calculated: the physical component summary scale and the mental component summary scale. Subscales range from 0 (maximum symptoms or limitations/ poor health) to 100 (no symptoms or limitations/ excellent health).

\section{Statistical analysis}

Data preparation and calculations were performed using the IBM SPSS version 24.0 for Windows (IBM Corp., Armonk, NY, USA). Per protocol, only completely filled in questionnaires were used for evaluation. Given the exploratory focus of the study, the significance threshold was set at a $p$ value $<0.05$. As variables were not found to be normally distributed according

Table 1. Hourly distribution of different multimodal components of two fibromyalgia day hospital programs

\begin{tabular}{|c|c|c|c|c|c|c|c|c|c|}
\hline \multirow[b]{2}{*}{$\begin{array}{l}\text { Therapeutic } \\
\text { elements }\end{array}$} & \multicolumn{3}{|c|}{ Psychoeducative elements } & \multirow{2}{*}{ 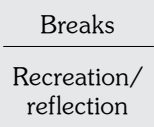 } & \multicolumn{4}{|c|}{ Physical medical elements } & \multirow{2}{*}{$\begin{array}{c}\text { Total } \\
4 \\
\text { weeks }\end{array}$} \\
\hline & $\begin{array}{c}\text { Medical } \\
\text { information }\end{array}$ & Psychology & $\begin{array}{c}\text { Behavioral } \\
\text { exercises }\end{array}$ & & $\begin{array}{c}\text { Physio-therapy } \\
\text { (active) }\end{array}$ & QiGong & $\begin{array}{c}\text { Occupational } \\
\text { therapy }\end{array}$ & $\begin{array}{c}\text { Hydro/balneo- } \\
\text { therapy }\end{array}$ & \\
\hline \multicolumn{10}{|l|}{ Hours } \\
\hline $\mathrm{P} 12$ & 8 & 16.5 & 8 & -- & 19 & 7 & 9.5 & 9.5 & 77.5 \\
\hline P20 & 15.5 & 23.5 & 13 & 23.5 & 25 & 6.5 & 12 & 14.5 & 133.5 \\
\hline
\end{tabular}


Table 2. Sociodemographic variables and duration of symptoms

\begin{tabular}{|c|c|c|c|c|}
\hline \multirow[b]{2}{*}{ Group } & \multicolumn{2}{|c|}{$P 12$ group $(n=140)$} & \multicolumn{2}{|c|}{ P20 group $(n=70)$} \\
\hline & $\%$ & Mean \pm SD & $\%$ & Mean \pm SD \\
\hline Age (year) & & $59.5 \pm 7.7$ & & $50.2 \pm 9.9$ \\
\hline Years of symptoms & & $12.1 \pm 9.7$ & & $10.0 \pm 9.0$ \\
\hline $\begin{array}{l}\text { Marital status } \\
\text { Married } \\
\text { Divorced } \\
\text { In relationship } \\
\text { Never married } \\
\text { Widowed } \\
\text { No information }\end{array}$ & $\begin{array}{c}58.6 \\
9.3 \\
\text { NA } \\
25.5 \\
5.7 \\
0.7\end{array}$ & & $\begin{array}{c}58.0 \\
18.8 \\
14.5 \\
7.2 \\
-- \\
1.4\end{array}$ & \\
\hline $\begin{array}{l}\text { Employment status } \\
\text { Working } \\
\text { Sick listed } \\
\text { Unemployed } \\
\text { Pensioned } \\
\text { Homemaker } \\
\text { No information }\end{array}$ & $\begin{array}{c}32.9 \\
12.9 \\
5.0 \\
27.1 \\
19.3 \\
2.8\end{array}$ & & $\begin{array}{c}42.0 \\
14.5 \\
13.0 \\
14.5 \\
14.5 \\
1.4\end{array}$ & \\
\hline $\begin{array}{l}\text { Education (year) } \\
\quad \leq 9 \\
9 \\
10 \\
12-13 \\
>13 \\
\text { No information }\end{array}$ & $\begin{array}{c}2.1 \\
48.5 \\
21.4 \\
7.9 \\
15.7 \\
4.3\end{array}$ & & $\begin{array}{c}1.4 \\
34.8 \\
30.4 \\
10.1 \\
21.7 \\
1.4\end{array}$ & \\
\hline $\begin{array}{l}\text { Total family income } \\
\quad<500 \\
500-1000 \\
1000-2000 \\
2000-3000 \\
>3000 \\
\text { No information }\end{array}$ & $\begin{array}{c}4.3 \\
8.6 \\
36.4 \\
21.4 \\
19.3 \\
10.0\end{array}$ & & $\begin{array}{c}10.1 \\
23.2 \\
23.2 \\
10.1 \\
26.1 \\
7.2\end{array}$ & \\
\hline
\end{tabular}

to the Kolmogorov-Smirnov test, the Wilcoxon rank-sum test was used for calculating the pre-post comparison within each group. The difference of treatment effects between the two groups was analyzed by comparing the $\Delta$ pre-post values utilizing the Mann-Whitney $\mathrm{U}$ test.

\section{RESULTS}

Demographics of the two groups are displayed in Table 2. After participation in the day hospital program, statistically significant improvement compared to baseline was observed for the SF36 subscales of physical-functioning, physical role functioning, social role functioning, mental health, bodily pain, vitality, general health, physical component, and mental component in the P12 group. In the P20 group, physical functioning, mental health, bodily pain, vitality, physical component, and mental component scales were significantly improved.

The most significant improvement from baseline in the SF36 was observed for the role-physical subscale. It was improved by $47.5 \%$ in the P12 group and $54.3 \%$ in the P20 group. The subscale of vitality was improved by $22.3 \%$ in the P12 group and $31.7 \%$ in the P20 group and the subscale of bodily pain was improved by 29.4\% from baseline in the P20 group.

In the P20 group, all FIQ subscales (apart from physical functioning scale that was worsened) were significantly improved after participation in the day hospital program compared to baseline before the program. In the P12 group, the FIQ subscales of pain, fatigue, morning tiredness, anxiety and depression as well as the number of days felt good were significantly improved. 
Table 3. Results of Fibromyalgia Impact Questionnaire before and after participation in two fibromyalgia day hospital programs

\begin{tabular}{|c|c|c|c|c|c|c|c|c|c|}
\hline \multirow[b]{3}{*}{ Items } & $\begin{array}{c}\text { Before day } \\
\text { hospital }\end{array}$ & $\begin{array}{c}\text { After day } \\
\text { hospital }\end{array}$ & \multirow[b]{2}{*}{$\begin{array}{c}\text { Improvement } \\
\text { to } \\
\text { baseline }\end{array}$} & \multirow[b]{2}{*}{$\begin{array}{c}\text { Statistical } \\
\text { significance } \\
\text { level }\end{array}$} & \multirow{2}{*}{$\begin{array}{c}\begin{array}{c}\text { Before day } \\
\text { hospital }\end{array} \\
\begin{array}{c}\text { P20 } \\
(\mathrm{n}=67)\end{array}\end{array}$} & \multirow{2}{*}{$\begin{array}{c}\begin{array}{c}\text { After day } \\
\text { hospital }\end{array} \\
\begin{array}{c}\text { P20 } \\
(\mathrm{n}=67)\end{array}\end{array}$} & \multirow[b]{2}{*}{$\begin{array}{c}\text { Improvement } \\
\text { to } \\
\text { baseline }\end{array}$} & \multirow[b]{2}{*}{$\begin{array}{c}\text { Statistical } \\
\text { significance } \\
\text { level }\end{array}$} & \multirow{2}{*}{$\begin{array}{c}\text { P12 vs. P20 } \\
\begin{array}{c}\text { Statistical } \\
\text { significance } \\
\text { level }\end{array}\end{array}$} \\
\hline & $\begin{array}{c}\mathrm{P} 12 \\
(\mathrm{n}=134)\end{array}$ & $\begin{array}{c}\mathrm{P} 12 \\
(\mathrm{n}=133)\end{array}$ & & & & & & & \\
\hline & Mean \pm SD & Mean \pm SD & $\%$ & $p$ & Mean \pm SD & Mean \pm SD & $\%$ & $p$ & $p$ \\
\hline \multicolumn{10}{|l|}{ FIQ subscale scores } \\
\hline Physical function (0-10) & $3.5 \pm 2.5$ & $3.2 \pm 2.3$ & 9.63 & 0.384 & $3.2 \pm 1.0$ & $3.3 \pm 1.7$ & -4.75 & 0.311 & 0.191 \\
\hline Days felt good (0-10, invers.) & $7.9 \pm 2.6$ & $7.1 \pm 2.8$ & 9.86 & $0.011^{*}$ & $6.9 \pm 2.5$ & $5.7 \pm 2.4$ & 17.51 & $0.001^{*}$ & $0.007^{*}$ \\
\hline Missed work (0-10) & $2.9 \pm 4.2$ & - & - & - & $2.9 \pm 4.1$ & - & - & - & - \\
\hline Total FIQ score (0-80) & $42.0 \pm 12.5$ & $39.7 \pm 14.0$ & 5.52 & 0.093 & $45.7 \pm 11.0$ & $37.9 \pm 12.6$ & 17.02 & $0.000^{*}$ & 0.165 \\
\hline \multicolumn{10}{|l|}{$\begin{array}{l}\text { FIQ Subscales } \\
\text { (VAS } 0-10 / 10 \text { ) }\end{array}$} \\
\hline Ability to do job & $6.2 \pm 2.4$ & - & - & & $6.1 \pm 2.4$ & - & - & - & - \\
\hline Pain & $6.7 \pm 2.1$ & $6.3 \pm 2.6$ & 6.42 & $0.019^{*}$ & $6.6 \pm 2.0$ & $6.0 \pm 2.1$ & 9.82 & $0.024^{*}$ & 0.423 \\
\hline Fatigue & $7.2 \pm 2.2$ & $6.8 \pm 2.5$ & 6.08 & $0.019^{*}$ & $7.2 \pm 2.1$ & $6.1 \pm 2.5$ & 14.76 & $0.002^{*}$ & 0.141 \\
\hline Morning tiredness & $7.3 \pm 2.2$ & $6.7 \pm 2.8$ & 8.00 & $0.008^{*}$ & $7.5 \pm 2.3$ & $6.1 \pm 2.7$ & 19.12 & $0.000^{*}$ & 0.059 \\
\hline Stiffness & $6.3 \pm 2.5$ & $6.2 \pm 2.9$ & 0.96 & 0.411 & $6.5 \pm 2.9$ & $5.0 \pm 2.7$ & 21.82 & $0.000^{*}$ & $0.001^{*}$ \\
\hline Anxiety & $4.7 \pm 3.0$ & $4.5 \pm 3.3$ & 5.92 & $0.034^{*}$ & $4.5 \pm 2.9$ & $3.4 \pm 2.7$ & 24.05 & $0.001^{*}$ & 0.152 \\
\hline Depression & $4.7 \pm 3.3$ & $4.3 \pm 3.3$ & 8.49 & $0.033^{*}$ & $4.4 \pm 2.8$ & $2.7 \pm 2.8$ & 38.51 & $0.012^{*}$ & 0.270 \\
\hline
\end{tabular}

In the comparison of the pre-post differences ( $\Delta$ pre-post) between the two hospital programs, a statistically significantly higher improvement in the P20 group compared to the P12 group was found for the FIQ subscale of stiffness ( $p=0.001,21.82 \%$ improvement compared to baseline) and the subscale of number of days felt good ( $p=0.007,17.51 \%$ improvement compared

Table 4. Results of Short Form 36 questionnaire before and after participation in two fibromyalgia day hospital programs

\begin{tabular}{|c|c|c|c|c|c|c|c|c|c|}
\hline \multirow[b]{3}{*}{ Items } & \multirow{2}{*}{$\begin{array}{c}\begin{array}{c}\text { Before day } \\
\text { hospital }\end{array} \\
\begin{array}{c}\text { P12 } \\
(n=139)\end{array}\end{array}$} & \multirow{2}{*}{$\begin{array}{c}\begin{array}{c}\text { After day } \\
\text { hospital }\end{array} \\
\begin{array}{c}\text { P12 } \\
(n=137)\end{array}\end{array}$} & \multicolumn{2}{|c|}{ Pre-post } & \multirow{2}{*}{$\begin{array}{c}\begin{array}{c}\text { Before day } \\
\text { hospital }\end{array} \\
\begin{array}{c}\text { P20 } \\
(n=69)\end{array}\end{array}$} & \multirow{2}{*}{$\begin{array}{c}\begin{array}{c}\text { After day } \\
\text { hospital }\end{array} \\
\begin{array}{c}\text { P20 } \\
(n=69)\end{array}\end{array}$} & \multicolumn{2}{|c|}{ Pre-post } & \multirow{2}{*}{$\begin{array}{c}\begin{array}{c}\text { P12 vs. P20 } \\
\text { ( } \begin{array}{c}\text { pre-post) } \\
\text { Statistical }\end{array} \\
\begin{array}{c}\text { significance } \\
\text { level }\end{array}\end{array}\end{array}$} \\
\hline & & & $\begin{array}{c}\text { Improvement } \\
\text { to } \\
\text { baseline }\end{array}$ & $\begin{array}{c}\text { Statistical } \\
\text { significance } \\
\text { level }\end{array}$ & & & $\begin{array}{c}\text { Improvement } \\
\text { to } \\
\text { baseline }\end{array}$ & $\begin{array}{c}\text { Statistical } \\
\text { significance } \\
\text { level }\end{array}$ & \\
\hline & Mean \pm SD & Mean \pm SD & $\%$ & $p$ & Mean \pm SD & Mean \pm SD & $\%$ & $p$ & $p$ \\
\hline \multicolumn{10}{|l|}{ SF36 subscales } \\
\hline Physical functioning & $44.6 \pm 20.4$ & $49.9 \pm 20.9$ & 11.7 & $0.000^{*}$ & $47.4 \pm 20.5$ & $55.0 \pm 18.9$ & 16.1 & $0.001^{*}$ & 0.822 \\
\hline Role-physical & $17.8 \pm 28.5$ & $26.3 \pm 34.6$ & 47.5 & $0.002^{*}$ & $15.1 \pm 26.7$ & $23.4 \pm 33.5$ & 54.3 & 0.12 & 0.869 \\
\hline Role-emotional & $46.6 \pm 44.8$ & $52.7 \pm 47.1$ & 13.1 & 0.077 & $50.0 \pm 44.1$ & $56.1 \pm 46.8$ & 12.12 & 0.471 & 0.994 \\
\hline Social functioning & $48.0 \pm 28.2$ & $54.8 \pm 28.2$ & 14.0 & $0.003^{*}$ & $54.0 \pm 26.7$ & $58.5 \pm 22.6$ & 8.3 & 0.80 & 0.858 \\
\hline Mental health & $49.6 \pm 21.8$ & $54.6 \pm 21.1$ & 10.1 & $0.000^{*}$ & $52.0 \pm 20.1$ & $59.9 \pm 20.9$ & 15.2 & $0.000^{*}$ & 0.195 \\
\hline Bodily pain & $28.2 \pm 15.8$ & $32.0 \pm 17.9$ & 13.7 & $0.006^{*}$ & $28.8 \pm 14.4$ & $37.3 \pm 14.4$ & 29.4 & $0.001^{*}$ & 0.142 \\
\hline General health & $37.4 \pm 18.7$ & $40.6 \pm 20.8$ & 8.5 & $0.018^{*}$ & $36.5 \pm 17.3$ & $38.6 \pm 18.9$ & 5.9 & 0.27 & 0.492 \\
\hline Physical component scale & $30.0 \pm 6.7$ & $32.0 \pm 8.0$ & 6.7 & $0.001^{*}$ & $29.9 \pm 7.0$ & $32.3 \pm 7.8$ & 8.2 & $0.017^{*}$ & 0.796 \\
\hline Mental component scale & $39.4 \pm 13.2$ & $42.1 \pm 13.1$ & 6.7 & $0.013^{*}$ & $40.3 \pm 12.9$ & $43.5 \pm 12.6$ & 8.0 & $0.046^{*}$ & 0.784 \\
\hline
\end{tabular}

P12: Twelve treatment days during four weeks; P20: Twenty treatment days during four weeks; SD: Standard deviation; SF36: Short Form 36; Statistical significance is displayed for pre-post comparison of both groups as well as for intergroup comparison (P12 versus P20). 
to baseline). The subscale of morning tiredness just missed statistical significance $(p=0.059$, $19.12 \%$ improvement compared to baseline). The improvement of the stiffness subscale by $21.82 \%$ compared to baseline in the P20 group was above the level that was described as the minimal clinically important difference (13\%).

The percentual improvement of the FIQ subscales was generally higher in the P20 group with a maximum improvement of $38.51 \%$ compared to baseline that was observed for the depression subscale. The only exception was the physical function scale in the P20 group with a higher impairment of $4.75 \%$. The pre-post FIQ and SF36 data are displayed in Tables 3 and 4, respectively.

\section{DISCUSSION}

To our knowledge, this retrospective analysis is the first to compare real-world outcome data of two specific fibromyalgia treatment programs with similar components but different intensity. This study has confirmed the observation of a slightly better fibromyalgia symptom relief in the long-term-approach in one randomized controlled trial, which compared a long- and a short-term multidisciplinary approach. ${ }^{22}$ The observation of another real-world data analysis of work disability of fibromyalgia patients after participation in either a specific fibromyalgia program or a non-specific musculoskeletal rehabilitation program seems to provide contradictory results. ${ }^{23}$ In their analysis, the musculoskeletal program, although being non-specific, was longer than the fibromyalgia program, which might have led to the observed results.

In our analysis, the FIQ subscales of stiffness and the number of days felt good were more effectively reduced in the five days per week program (P20) than in the three days per week program (P12). We believe that the significant improvement in the FIQ item of days felt good in our study was caused by the daily treatments. However, such a result may also be attributed to the different setting and requirements of the day hospital program compared to daily life. The FIQ subscale of stiffness has been shown to be correlated to other symptom scores in fibromyalgia. ${ }^{24}$ Accordingly, and in line with the observed improvements of the other FIQ items in the pre-post comparison in our evaluation, clinically relevant improvement of fibromyalgia symptoms was shown. Improvements were clearly above the level of $13.2 \%$ for the minimal clinically important difference for the stiffness scale of the FIQ. ${ }^{25}$ Furthermore, the observed improvement of $17.02 \%$ in the FIQ total score in the P20 group was also clearly above the minimal clinically important difference of $14 \%{ }^{25}$ compared to only $5.52 \%$ in the P12 group. The difference between the two groups was, however, not statistically significant.

Our observations are of special clinical interest because they support a decision towards a more intensive treatment for patients. Additionally, they demonstrate that the physical and psychological challenge of the five days per week program is appropriate and does not overtax the patients. The P12 program had initially been created under the assumption that a less intensive program is more suitable for patients suffering from fibromyalgia, as it has previously been shown that fibromyalgia patients have limited physical resources. ${ }^{26,27}$ Our results can thus encourage healthcare providers to offer a more intensive therapy.

Additionally, it would be interesting to know why the strongest differential effect was observed for stiffness: It might be hypothesized that this effect was caused by the intensification of certain elements of the program more than others. The significant increase in the number of days the patient felt good might be due to the increased hours of psychological and behavioral therapy. In respect to the improvement of stiffness, the element of the physical treatment that was intensified the most in the P20 group was hydrotherapy. Balneotherapy, hydrotherapy or aquatic exercises have previously been shown to ease fibromyalgia symptoms ${ }^{28-30}$ and positively influence stiffness in fibromyalgia. ${ }^{31,32}$ Furthermore, balneotherapy has been shown to have beneficial effects as an add-on therapy. ${ }^{33,34}$ Another factor adding to the beneficial effect might be the general increase in daily activity and reduction of sedentary time throughout the P20 program. It has been observed that fibromyalgia patients tend to spend more inactive time than healthy controls ${ }^{35}$ and physical exercise can reduce symptom intensity. ${ }^{36}$ Together with our observations, all these findings underline the importance of synergistic effects in the interdisciplinary setting. 
The daily engagement of patients in the P20 program might be reflected in the fact that the FIQ subscale of physical function was worsened compared to baseline. This contradiction of the improvement in all other scales can be easily explained by the composition of the subscale. Patients have rated to what extent they were able to perform a number of daily tasks like shopping, gardening, washing clothes or dishes or preparation of food throughout the last week. After a full day program at the hospital, patients probably did not have as much time as usual for their daily tasks. This assumption is strengthened by the improved subscale of physical functioning of the SF36 in both groups. In this subscale, patients were asked about the same activities; however, the question was posed slightly differently. It asked about the extent of limitations in the activities due to health issues, whereas FIQ simply questioned if the patients were able to perform the activities at all. Also, the highest percentual improvements from baseline were observed for the SF36 subscale of physical role functioning that inquires about the restrictions in physical activity due to health limitations during the last four weeks.

The observation that more subscales of the SF36 were significantly changed in the P12 group in the pre-post comparison than in the P20 group is most likely due to the almost doubled number of participants in the P12 group. This is confirmed by the percentual changes that show a higher improvement for most subscales in the P20 group than the P12 group.

There were some limitations to our evaluation, most of which were caused by the evaluation of real-world data that were originally intended for clinical use and not for scientific analysis. This has led to a limited number of completely filled in questionnaires, so the number of available datasets for evaluation was much lower than the number of the participants in the day hospital program. This might have resulted in a selection bias of dropouts due to physical symptoms or inability to complete the program. In general, the dropout rate has been low in both day hospital programs (around 0.1\%) and thus unlikely to play a role. Additionally, this would apply for both groups and should therefore not influence the comparison of the groups. Furthermore, there were some differences of age and symptom duration between the two groups, although we believe that they were overcome by the comparison of changes from baseline. However, it is still possible that patients in the P12 group that were averagely 10 years older than patients in the P20 group had more difficulties in participating in physical activities even if those were low-impact activities suitable for chronic pain patients. Another limitation is the fact that no long-term follow-up was performed. Consequently, the observed effects should be further evaluated in a larger group of patients with long-term follow-up.

In conclusion, both interdisciplinary day hospital programs were able to reduce fibromyalgia symptoms. The program with five treatment days per week was more effective in reducing fibromyalgia symptoms and improving health related quality of life than the program with three treatment days per week.

\section{Declaration of conflicting interests}

The authors declared no conflicts of interest with respect to the authorship and/or publication of this article.

\section{Funding}

Supported by the FöFoLe (Förderung von Forschung und Lehre) program of the Medical Faculty of the University of Munich.

\section{REFERENCES}

1. Lacasse A, Bourgault $P$, Choinière $M$. Fibromyalgiarelated costs and loss of productivity: a substantial societal burden. BMC Musculoskelet Disord 2016;17:168.

2. Thompson JM, Luedtke CA, Oh TH, Shah ND, Long $\mathrm{KH}$, King $\mathrm{S}$, et al. Direct medical costs in patients with fibromyalgia: Cost of illness and impact of a brief multidisciplinary treatment program. Am J Phys Med Rehabil 2011;90:40-6.

3. Wolfe F, Clauw DJ, Fitzcharles MA, Goldenberg DL, Katz RS, Mease P, et al. The American College of Rheumatology preliminary diagnostic criteria for fibromyalgia and measurement of symptom severity. Arthritis Care Res (Hoboken) 2010;62:600-10.

4. Bernardy K, Klose P, Welsch P, Häuser W. Efficacy, acceptability and safety of cognitive behavioural therapies in fibromyalgia syndrome - A systematic review and meta-analysis of randomized controlled trials. Eur J Pain 2018;22:242-60. 
5. Welsch P, Bernardy K, Derry S, Moore RA, Häuser W. Mirtazapine for fibromyalgia in adults. Cochrane Database Syst Rev 2018;8:CD012708.

6. Welsch P, Üçeyler N, Klose P, Walitt B, Häuser $\mathrm{W}$. Serotonin and noradrenaline reuptake inhibitors (SNRIs) for fibromyalgia. Cochrane Database Syst Rev 2018;2:CD010292.

7. Aman MM, Jason Yong R, Kaye AD, Urman RD. Evidence-Based Non-Pharmacological Therapies for Fibromyalgia. Curr Pain Headache Rep 2018;22:33.

8. Thorpe J, Shum B, Moore RA, Wiffen PJ, Gilron I. Combination pharmacotherapy for the treatment of fibromyalgia in adults. Cochrane Database Syst Rev 2018;2:CD010585.

9. Üçeyler N, Sommer C, Walitt B, Häuser W. WITHDRAWN: Anticonvulsants for fibromyalgia. Cochrane Database Syst Rev 2017;10:CD010782.

10. Johnson MI, Claydon LS, Herbison GP, Jones G, Paley CA. Transcutaneous electrical nerve stimulation (TENS) for fibromyalgia in adults. Cochrane Database Syst Rev 2017;10:CD012172.

11. Baranowsky J, Klose P, Musial F, Häuser W, Dobos G, Langhorst J. Qualitative systemic review of randomized controlled trials on complementary and alternative medicine treatments in fibromyalgia. Rheumatol Int 2009;30:1-21.

12. Langhorst J, Klose P, Dobos GJ, Bernardy K, Häuser W. Efficacy and safety of meditative movement therapies in fibromyalgia syndrome: a systematic review and meta-analysis of randomized controlled trials. Rheumatol Int 2013;33:193-207.

13. Sommer C, Alten R, Bär KJ, Bernateck M, Brückle $\mathrm{W}$, Friedel E, et al. Drug therapy of fibromyalgia syndrome : Updated guidelines 2017 and overview of systematic review articles. Schmerz 2017;31:274-84.

14. Macfarlane GJ, Kronisch C, Dean LE, Atzeni F, Häuser W, Fluß E, et al. EULAR revised recommendations for the management of fibromyalgia. Ann Rheum Dis 2017;76:318-28.

15. Choi BC, Pak AW. Multidisciplinarity, interdisciplinarity and transdisciplinarity in health research, services, education and policy: 1. Definitions, objectives, and evidence of effectiveness. Clin Invest Med 2006;29:351-64.

16. Häuser W, Bernardy K, Arnold B, Offenbächer M, Schiltenwolf M. Efficacy of multicomponent treatment in fibromyalgia syndrome: a meta-analysis of randomized controlled clinical trials. Arthritis Rheum 2009;61:216-24.

17. Schiltenwolf $M$, Eidmann U, Köllner V, Kühn $T$, Offenbächer M, Petzke F, et al. Multimodal therapy of fibromyalgia syndrome: Updated guidelines 2017 and overview of systematic review articles. Schmerz 2017;31:285-8.

18. Giusti EM, Castelnuovo G, Molinari E. Differences in multidisciplinary and interdisciplinary treatment programs for fibromyalgia: a mapping review. Pain Res Manag 2017;2017:7261468.
19. Offenbaecher M, Waltz M, Schoeps P. Validation of a German version of the Fibromyalgia Impact Questionnaire (FIQ-G). J Rheumatol 2000;27:1984-8.

20. Ware JE Jr, Sherbourne CD. The MOS 36-item shortform health survey (SF-36). I. Conceptual framework and item selection. Med Care 1992;30:473-83.

21. Bullinger M. German translation and psychometric testing of the SF-36 Health Survey: preliminary results from the IQOLA Project. International Quality of Life Assessment. Soc Sci Med 1995;41:1359-66.

22. Saral I, Sindel D, Esmaeilzadeh S, Sertel-Berk $\mathrm{HO}$, Oral A. The effects of long- and short-term interdisciplinary treatment approaches in women with fibromyalgia: a randomized controlled trial. Rheumatol Int 2016;36:1379-89.

23. Suoyrjö H, Oksanen T, Hinkka K, Pentti J, Kivimäki M, Klaukka T, et al. A comparison of two multidisciplinary inpatient rehabilitation programmes for fibromyalgia: a register linkage study on work disability. J Rehabil Med 2009;41:66-72.

24. Bennett R, Russell IJ, Choy E, Spaeth M, Mease P, Kajdasz D, et al. Evaluation of patient-rated stiffness associated with fibromyalgia: a post-hoc analysis of 4 pooled, randomized clinical trials of duloxetine. Clin Ther 2012;34:824-37.

25. Bennett RM, Bushmakin AG, Cappelleri JC, Zlateva G, Sadosky AB. Minimal clinically important difference in the fibromyalgia impact questionnaire. J Rheumatol 2009;36:1304-11.

26. Güler $H$, Yildizgören MT, Üstün N, Paksoy $H$, Turhanoğlu AD. Isokinetic assessment of the wrist muscles in females with fibromyalgia. Arch Rheumatol 2016;31:215-20.

27. Genç H, Atasever M, Duyur Çakit B, Seval M, Koç A. The effects of fibromyalgia syndrome on physical function and psychological status of pregnant females. Arch Rheumatol 2017;32:129-40.

28. Fioravanti A, Manica P, Bortolotti R, Cevenini G, Tenti S, Paolazzi G. Is balneotherapy effective for fibromyalgia? Results from a 6-month doubleblind randomized clinical trial. Clin Rheumatol 2018;37:2203-12.

29. Sevimli D, Kozanoglu E, Guzel R, Doganay A. The effects of aquatic, isometric strength-stretching and aerobic exercise on physical and psychological parameters of female patients with fibromyalgia syndrome. J Phys Ther Sci 2015;27:1781-6.

30. Bidonde J, Busch AJ, Webber SC, Schachter CL, Danyliw A, Overend TJ, et al. Aquatic exercise training for fibromyalgia. Cochrane Database Syst Rev 2014;10:CD011336.

31. Lima TB, Dias JM, Mazuquin BF, da Silva CT, Nogueira RM, Marques AP, et al. The effectiveness of aquatic physical therapy in the treatment of fibromyalgia: a systematic review with meta-analysis. Clin Rehabil 2013;27:892-908. 
32. McVeigh JG, McGaughey $\mathrm{H}$, Hall M, Kane P. The effectiveness of hydrotherapy in the management of fibromyalgia syndrome: a systematic review. Rheumatol Int 2008;29:119-30.

33. Kurt EE, Koçak FA, Erdem HR, Tuncay F, Kelez F. Which non-pharmacological treatment is more effective on clinical parameters in patients with fibromyalgia: balneotherapy or aerobic exercise? Arch Rheumatol 2016;31:162-9.

34. Koçyiğit BF, Gür A, Altındağ Ö, Akyol A, Gürsoy $\mathrm{S}$. Comparison of education and balneotherapy efficacy in patients with fibromyalgia syndrome:
A randomized, controlled clinical study. Agri 2016;28:72-8.

35. Segura-Jiménez V, Álvarez-Gallardo IC, EstévezLópez F, Soriano-Maldonado A, Delgado-Fernández $\mathrm{M}$, Ortega FB, et al. Differences in sedentary time and physical activity between female patients with fibromyalgia and healthy controls: the al-Ándalus project. Arthritis Rheumatol 2015;67:3047-57.

36. Bidonde J, Busch AJ, Schachter CL, Overend TJ, Kim SY, Góes SM, et al. Aerobic exercise training for adults with fibromyalgia. Cochrane Database Syst Rev 2017;6:CD012700. 